\title{
Analysis of chemical structure and characteristics of building materials based on element chemistry
}

\author{
ZHAO Yanlong ${ }^{1}$, BAI Jitao ${ }^{2}$, LIANG Jiahe ${ }^{3}$, ZHANG Simiao $^{4}$ \\ 1. School of Chemical Engineering and Technology, Tianjin University, Tianjin 300072, China; \\ 2. School of Civil Engineering, Tianjin University, Tianjin 300072, China; \\ 3. School of Architecture, Tianjin University, Tianjin 300072, China; \\ 4. College of Intelligence and Computing, Tianjin University, Tianjin 300072, China
}

\begin{abstract}
Elements in accordance with a certain proportion and spatial arrangement constitute the microstructure of the building materials, which lead to a specific property and function in the macro. From the perspective of element chemistry, we divide common building materials into three categories: silicon-based building materials, carbon-based building materials and iron-based building materials. Then, with the knowledge of valence electron structure and electronic configuration, we systematically expound the three-element building materials system. According to that division mode, we explain the microstructural causes and macroscopic properties of the three-element building materials system through the valence bond theory, so as to provide references for the development and application of building materials.
\end{abstract}

\section{Introduction}

Human beings have created a wide variety of building materials in thousands of years of construction practice. These materials can be divided into six general categories: mineral building materials, wood, concrete, metal, glass and plastic ${ }^{[1]}$. Nowadays, with the rapid development of materials science, new building materials with special functions, such as phase change composite materials, memory metal materials, and degradable polymer materials, have continuously appeared. However, due to high cost and relatively immature technology, these building materials has not been widely used in construction engineering, for the reason that its promotion has greater uncertainty. Therefore, this article restricts the research object to the above-mentioned six general building materials.

Modern buildings are generally designed from building materials ${ }^{[2]}$, while most of the current research on building materials focuses on the macro-physical and mechanical properties of the materials instead of the more essential element chemical characteristics. In this paper, starting from the element composition and microstructure of the six general building materials, based on the principles of element chemistry, the basic micro element modules are extracted from the macro general building materials. Then, the relationships between the chemical nature of the element and the properties of the macro building materials are explored, so as to clarify the characteristics and defects of the building materials. According to that, a reference from the element chemistry point of view for the screening and application of building materials and the development of new building materials is provided.

\section{General Building Materials and Their Element Composition}

\subsection{Induction of the History of Architectural Development}

The development history of building materials can be simply expressed as a timeline chart shown in Fig. 1. In the Stone Age, humans usually searched for natural caves or built simple shacks with vegetation to separate the internal living environment from the external environment. During this period, the building materials used were all natural building materials such as stone, wood or soil. In the subsequent ancient civilizations of Egypt and Mesopotamia, people began to use the most abundant aluminosilicate mineral materials in the earth's crust to fire bricks and tiles ${ }^{[3]}$, and gradually explored artificial glass ${ }^{[4]}$. Moreover, the Egyptians also used lime mortar in the construction of the pyramids. By the time of ancient Greece and ancient Rome, wood has been more widely used in the construction system. In addition to using natural materials such as stone and wood, the Romans also invented the famous opus caementicium concrete, which is made of pumice aggregate, quicklime and pozzolan, with higher strength and better water 
resistance. From then on to the industrial revolution, building materials entered a stage of slow development. During this period, progress in the field of architecture was mainly concentrated in architectural art and construction techniques, while no landmark breakthroughs were seen in building materials.

After the first industrial revolution, the output of steel rose rapidly. Moreover, the architectural form of cast iron frame and glass curtain wall began to appear and was widely used. At the beginning of the 19th century, Portland cement was invented. Subsequently, the engineering community gradually figured out the matching form of reinforced concrete and continues to use it today. In the middle of the twentieth century, synthetic polymer materials with strong chemical stability have gradually been applied in the field of construction by virtue of their unique mechanical properties. So far, six categories of concrete、 mineral building materials、 glass、 wood、 plastic and metal building materials have all appeared.

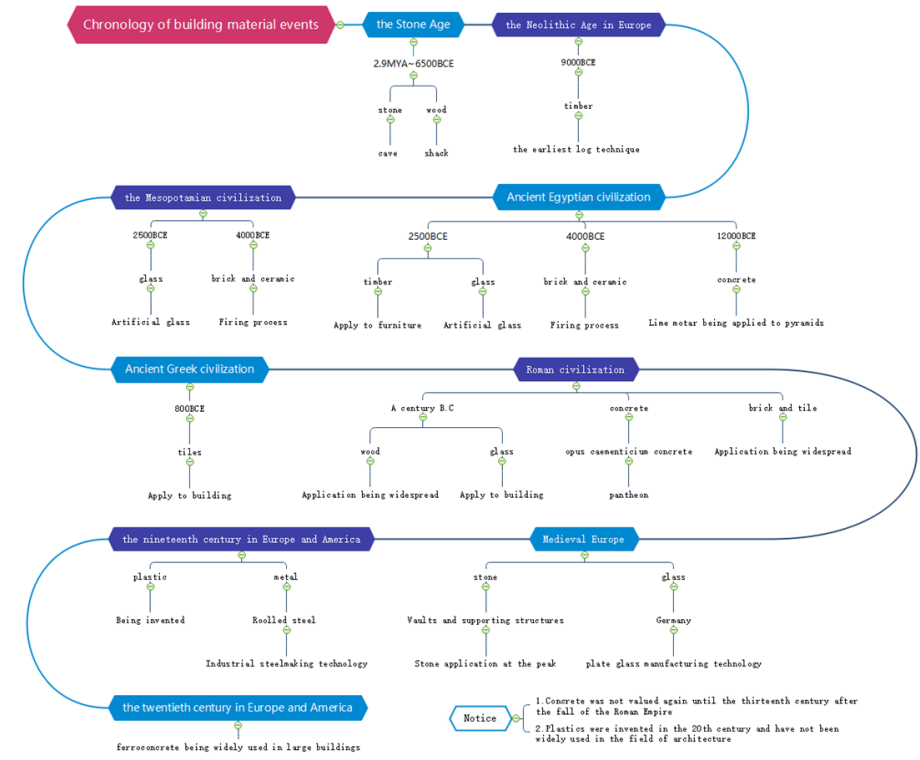

Fig. 1 Timeline of the development of building materials

\subsection{Element Composition of General Building Materials}

The six general building materials include mineral building materials, concrete, glass, wood, plastic and metal building materials. Among them, mineral building materials specifically include stone, ceramics and bricks. The main components or production materials of mineral building materials, concrete and glass are all aluminosilicates. Wood and plastic are both hydrocarbon polymers. Metal building materials are most commonly iron.

\subsubsection{Mineral Building Materials, Concrete and Glass}

Engineering geology usually divides natural stone into magmatic rock, sedimentary rock and metamorphic $\operatorname{rock}^{[5]}$. Among them, magmatic rock-type building stones usually include granite and basalt, sedimentary rock-type building stones include limestone and sandstone, and metamorphic rock-type building stones usually include marble, slate and gneiss ${ }^{[1]}$. The chemical composition of the main building stones is shown in Table 1 .

According to Table 1, it is not difficult to find that aluminosilicate is the most important component of stone. Since the raw material soil for firing bricks and ceramics is mainly derived from weathering of rocks, aluminosilicate is also the main component of bricks and ceramics.

Ordinary silicate concrete consists of six parts of water, four parts of coarse aggregate (gravel), two parts of fine aggregate (sand) and one part of cement. The main component of cement is Portland cement clinker, the hydraulic gel material (the main components are tricalcium silicate, dicalcium silicate, tricalcium aluminate and tetracalcium aluminate), $0 \sim 5 \%$ limestone or granulated blast furnace slag, with an appropriate amount of finely ground gypsum ${ }^{[6]}$.

The main component of glass is silica. Depending on the type, it may also contain ingredients such as sodium oxide, calcium oxide, and magnesium oxide. 
Table 1 Chemical composition of major building stones

\begin{tabular}{c|c|c|c|c|c|c}
\hline \multirow{2}{*}{ Rock types } & \multicolumn{4}{|c|}{ Natural rocks } & \multicolumn{2}{c}{ Metamorphic rock } \\
\cline { 2 - 6 } & \multicolumn{2}{|c|}{ Magmatic rock } & \multicolumn{2}{c}{ Sedimentary rock } & Marble & Slate \& Gneiss \\
\hline Rock name & Granite & Basalt & Limestone & Sandstone & $\begin{array}{c}\text { Quartz \& } \\
\text { carbonate }\end{array}$ & Aluminosilicate \\
\hline $\begin{array}{c}\text { Main chemical } \\
\text { composition }\end{array}$ & Aluminosilicate & $\begin{array}{c}\text { Calcium } \\
\text { carbonate }\end{array}$ & Aluminosilicate \\
\hline
\end{tabular}

\subsubsection{Wood and plastic}

Both wood and plastic are carbon-based organic polymers.

In history, wood has been used as the main structural building material for a long time, and an independent wood structure building system has gradually been derived from it. The main part that gives wood strength is the xylem. The xylem is composed of rigid elongated cells. The main components of the cell wall are cellulose, hemicellulose, and lignin, which account for 40-50\%, 20-30, and 20-30\%, respectively.

Cellulose is polymerized by $\beta$-1,4-glycosidic linkage of D-glucose monomer ${ }^{[7]}$, as shown in Fig. 2. The long molecular chains of cellulose are arranged in parallel to form cellulose bundles.

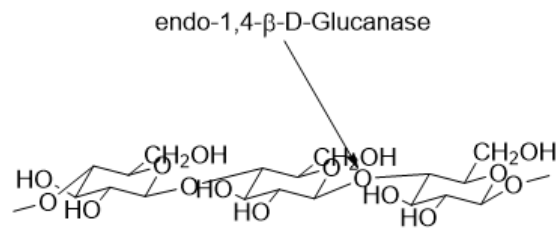

Fig. 2 Molecular structure of cellulose polymer

Hemicellulose is another polysaccharide that coexists with cellulose. Different from homopolysaccharide cellulose, when forming hemicellulose, generally two or more monosaccharides are first polymerized to form a branched heteropolysaccharide. One of the more important ones is polyxylose ${ }^{[8]}$. As shown in Fig. 3, its structure is different from cellulose in that the flat $\mathrm{CH}_{2} \mathrm{OH}$ at the $\mathrm{C} 5$ position of each monosaccharide of cellulose is replaced by hydrogen.

$$
\text { O. } \mathrm{HO}^{-\mathrm{OHO}}
$$

Fig. 3 Molecular structure of polyoxymose polymer

Lignin is surrounded by cell walls of tube bundles such as wood fibers. It is a three-dimensional network of amorphous polymers connected by phenylpropane derivative monomers with ether bonds and a small amount of carbon bonds. The basic structural units are shown in Fig. 4, which are mainly guaiacylpropane units, syringylpropane units and p-hydroxyphenylpropane units $^{[9]}$.

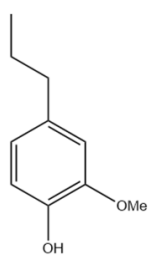

(a)

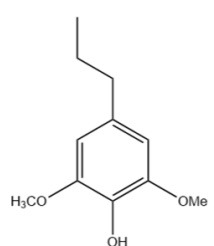

(b)

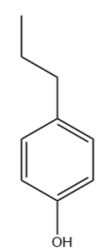

(c)
Fig. 4 Basic structural unit of lignin

(a) Unit of guaiac-based propane; (b) Unit of syringyl propane;

(c) Unit of para-hydroxyphenylpropane

Plastics are polymer compounds formed by the polymerization of unsaturated hydrocarbon monomers through carbon-carbon bonds, ester bonds or ether bonds (a small amount), usually by cross-linking multiple long carbon chain macromolecules. Plastics are mainly used in power systems and pipeline equipment in construction projects, but there is a trend toward major structural materials in some areas ${ }^{[10]}$.

\subsubsection{Metal Building Material}

Metal building materials have a metal crystal structure with good electrical conductivity, thermal conductivity and ductility, and are easy to roll into shape. At the same time, metal building materials usually have high strength, so they can be used as structural stress materials. At present, the most used metal building material is iron. In the 19th century, the popular construction method of pig iron structure and iron frame with glass, the metal building materials used were mainly cast iron. Cast iron is brittle, has poor plastic deformation ability, and has a small emergency capacity ${ }^{[1]}$, so many elements are usually added to iron in modern times to synthesize building steel with better properties.

\section{Three-element Building Materials Division System}

According to the element composition of general building materials, it can be divided into silicon-based, carbon-based and iron-based ternary building materials systems. Silicon-based building materials include mineral building materials, concrete and glass with aluminosilicate as the main component. This type of material takes silicon as its core to form its microstructure. Carbon-based building materials include hydrocarbon polymer materials such as wood and plastics. The carbon chain formed with carbon as the core 
constitutes the microstructure of these materials. Iron-based building materials represent the main part of metal building materials, mainly including iron-based alloys. The chemical nature of the three elements of silicon, carbon, and iron in the electronic configuration, valence electron structure and valence bond structure determines their tendency to form substances, and ultimately manifests as the difference in the macroscopic morphology and properties of the materials.

There are two obvious characteristics of the three-dimensional building material system. Firstly, silicon and carbon, which belong to the IVA group of the periodic table, have similar four-electron valence electron structure, but form aluminosilicate ion crystal building materials (silicon-based) and hydrocarbon polymer building materials (carbon-based), with very different properties. Secondly, iron is mainly used in construction projects in elemental substance and metal crystal microstructure, which is different from the compound forms of silicon-based and carbon-based building materials.

\subsection{Silicon-based and Carbon-based Building Materials System}

\subsubsection{Essential Differences in Electronic Configuration}

Both silicon and carbon belong to group IVA of the periodic table and have the same valence structure. Moreover, both can form four covalent bonds through four orbitals and have the tendency to form long-chain molecular structures through covalent bonds. However, the two elements have derived silicon-based building materials with aluminosilicate ion crystals as the main component and carbon-based building materials with polymer hydrocarbons as the main component. From the perspective of electronic configuration, there are two reasons for the above difference: one is the influence of the atomic radius. Specifically, the relative atomic radius of silicon is larger than that of carbon atoms. The other is the difference in electron orbits. To be specific, silicon atoms have one more $3 \mathrm{~d}$ orbital than carbon atoms.

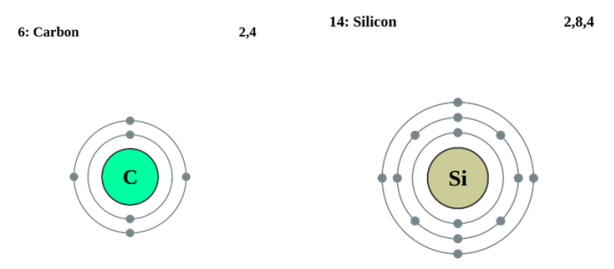

Fig. 5 Electronic configuration of carbon and silicon

The silicon element is located in the third period, and the electronic configuration is $1 s^{2} 2 s^{2} 2 p^{6} 3 s^{2} 3 p^{2}$; the carbon element is located in the second period, and the electronic configuration is $1 \mathrm{~s}^{2} 2 \mathrm{~s}^{2} 2 \mathrm{p}^{2}$. Although silicon and carbon belong to the same main group, silicon has one more period than carbon, which means one more electron layer. And it causes the covalent radius of silicon atoms to reach $118 \mathrm{pm}$, which is significantly larger than the atomic radius of carbon atoms of $77 \mathrm{pm}^{[12]}$. Moreover, it also makes the silicon an empty $3 \mathrm{~d}$ orbital.

\subsubsection{Oxygen-philic Nature of Silicon}

Silicon atoms easily form tetrahedral structural units $\left[\mathrm{SiO}_{4}\right]$ with oxygen atoms, thereby forming long chains, long bands or grid-like three-dimensional structures in the form of sharing oxygen atoms. Under normal circumstances, carbon atoms cannot form tetrahedral structural units $\left[\mathrm{CO}_{4}\right]$ with oxygen atoms, so it is impossible to form a building material system similar to silicon.

Such oxygen-philic difference depends primarily on the difference in atomic radius. The silicon atom has a large radius. When forming a tetrahedral structure, the four oxygen atoms can be stably connected to the silicon atom in the form of covalent bonds. The radius of carbon atoms is small. If a tetrahedral structure $\left[\mathrm{CO}_{4}\right]$ is formed, the four $\mathrm{C}-\mathrm{O}$ covalent single bonds will be too crowded and electron cloud repulsion will occur. The only way to form a stable spatial structure is to increase the length of the carbon-oxygen bond. However, the increase of the bond length will reduce the overlapping area of the orbital electron cloud, the $\sigma$ covalent bond energy will decrease, and the structure will still be unstable. Therefore, compared with silicon of the same main group, carbon is difficult to form a chemical structure in the form of a carbon-oxygen tetrahedron.

Another reason for the difference in oxygen-philic is the difference in the electronic orbits of the two. Silicon atoms have one more empty $3 \mathrm{~d}$ orbital than carbon atoms. Therefore, in the formation of $\left[\mathrm{SiO}_{4}\right]$ tetrahedral structure, in addition to the covalent single bond $\mathrm{Si}-\mathrm{O}$, the lone electron pair of oxygen atoms can also form $\mathrm{p}$-d $\mathrm{d}$ bonds with the empty orbital of $\mathrm{Si}$ atoms. And that increases the overlap area of the electron cloud, improves the bond energy, and makes the chemical structure more stable.

In addition, it is also possible to make a preliminary judgment on the stability of bonding from the perspective of bond energy alone. According to the data in Table 2, the $\mathrm{Si}-\mathrm{Si}$ bond energy is much lower than the $\mathrm{Si}-\mathrm{O}$ bond energy. Therefore, in an environment where oxygen is widely distributed, unstable $\mathrm{Si}-\mathrm{Si}$ bonds tend to form Si-O bonds with higher bond energy, thereby forming a stable $\left[\mathrm{SiO}_{4}\right]$ tetrahedral structure. It is the oxygen-philic of silicon that determines the chemical structure of silicon-based building materials, which is characterized by the connection of silicon-oxygen tetrahedra and silicon-oxygen tetrahedra.

Of course, carbon atoms and oxygen atoms can form bonds to form compounds for use in building materials systems. Oxygen elements usually appear in the form of ether bonds in carbon-based building materials and serve as the connection structure between monomers. In addition, in mineral building materials, it is also often present in carbonate in the form of flat regular triangle carbonate $\left[\mathrm{CO}_{3}\right]^{2-}$. 
Table 2 Main parameters of chemical bonding of carbon and silicon

\begin{tabular}{|c|c|c|c|c|c|}
\hline $\begin{array}{c}\text { Chemical } \\
\text { bonds }\end{array}$ & $\begin{array}{l}\text { Bond length } \\
\text { /pm }\end{array}$ & $\begin{array}{c}\text { Bond energy } \\
/ \mathrm{kJ} . \mathrm{mol}^{-1}\end{array}$ & $\begin{array}{c}\text { Chemical } \\
\text { bonds }\end{array}$ & Bond length /pm & $\begin{array}{c}\text { Bond energy } \\
\text { /kJ.mol }{ }^{-1}\end{array}$ \\
\hline $\mathrm{C}-\mathrm{C}$ & 137 & 356 & $\mathrm{Si}-\mathrm{Si}$ & 235 & 226 \\
\hline $\mathrm{C}-\mathrm{H}$ & 109 & 413 & $\mathrm{Si}-\mathrm{H}$ & 148 & 318 \\
\hline $\mathrm{C}-\mathrm{O}$ & 143 & 336 & Si-O & 166 & 452 \\
\hline
\end{tabular}

\subsubsection{Connectivity Nature of Carbon}

Connectivity refers to the property that atoms of the same element are connected to each other through covalent bonds to form a chain, ring or three-dimensional framework $^{[13]}$. The main composition of carbon-based building materials is a hydrocarbon polymer with a carbon chain as the skeleton, and the remaining valence orbitals are filled with hydrogen atoms to form a $\mathrm{C}-\mathrm{H}$ covalent bond. However, the connectivity of silicon atoms is poor. Moreover, the formed $\mathrm{Si}-\mathrm{Si}$ covalent single bond has a long bond length, low bond energy, and is extremely unstable. Therefore, it is difficult to form a "silicon chain" or a silicon-hydrogen polymer similar to carbon-based materials.

The main factors leading to differences in connectivity are also caused by differences in atomic radii and electronic configurations. Due to the large radius of silicon atoms, the orbital electron cloud of the carbon-oxygen bond has a small overlap area, large bond length, and low bond energy (refer to Table 2), so it is far less stable than carbon-carbon bonds. In the same way, when forming unsaturated bonds similar to carbon-carbon double bonds and carbon-carbon triple bonds, the silicon atom has a large radius and a long bond, leading to the poor overlap of $p$-p orbital electron cloud. In that case, the stability is also worse than that of the carbon bond.

Therefore, the carbon element, with its good connectivity, forms a carbon-based building material system that is different from silicon-based building materials.

\subsection{Iron-based building material}

\subsubsection{Microstructure}

Different from the silicon-based and carbon-based building material systems, the iron-based building material is mainly a metal crystal structure in the form of an elementary substance rather than a compound formed by a valence bond. The core element of iron-based building materials, iron, belongs to group VIII at the fourth period, with an electronic configuration of [Ar] $3 d^{6} 4 s^{2}$ and a valence electron structure of $3 d^{6} 4 s^{2}$. According to the modified covalent bond theory ${ }^{[14]}$, each iron atom has eight valence electrons, which are called "free electrons". "Free electrons" flow freely between iron atoms to form "free electron gas", and iron ions are immersed in the "free electron gas". This force that binds iron ions through the continuous movement of free electrons is called a metal bond. From the perspective of electron delocalization, the metal bond of the free electron model is the same as the delocalized $\pi$ bond, but the iron atom does not need to be coplanar as required by the covalent delocalization bond. Therefore, it can form bonds in all directions in space without saturability and directionality. In addition, in the metal crystal, the iron atoms will be arranged as closely as possible to increase the space utilization rate, thereby forming a stable metal crystal.

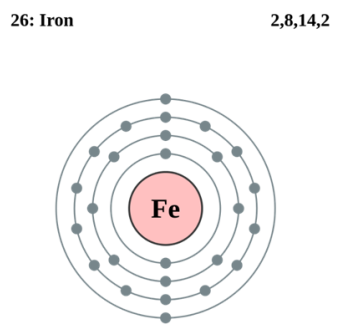

Fig. 6 Electronic configuration of iron

\subsubsection{Mechanical Properties}

By controlling the carbon content and the incorporation of other elements in the steel smelting process, construction steel with good strength and toughness can be obtained. Compared with silicate materials such as stone and concrete, steel has higher tensile strength, so its use in reinforced concrete structures can make up for the lack of concrete tensile strength ${ }^{[15]}$. Due to the high tensile and compressive strength of steel, it can also be used alone as a structural material to construct steel structures.

In addition, according to the modified covalent bond theory, when the iron crystal is impacted by an external force, the atoms between the layers will undergo relative displacement, but the "free electron" connection effect has not changed, that is, the metal bond has not been destroyed. The microscopic crystal structure remains stable, but appears to be squashed or elongated macroscopically, so it has good ductility. In modern steel structures, this characteristic of metal gives the building a certain degree of flexibility, making the building more resistant to deformation and higher emergency capacity. 


\section{Valence Bond Explanation for Three-element Building Materials' Characteristics}

\subsection{Bonding Characteristics of Silicon-based Building Materials}

\subsubsection{Si-O and Al-O}

Silicon-based building materials use $\left[\mathrm{SiO}_{4}\right]$ as the basic unit and share oxygen atoms to form a three-dimensional structure such as a chain, a ring, or a network. In the three-dimensional structure composed of silicon-oxygen tetrahedrons, oxygen atoms are closely arranged in a lattice, and the charge is balanced by the cations existing in the tetrahedron, octahedron or other vacancies.

In silicon-based building materials, aluminum and silicon usually form aluminosilicates. From the point of view of electronic configuration, aluminum is located in group IIIA of the third period, and the electronic configuration is $[\mathrm{Ne}] 3 \mathrm{~s}^{2} 3 \mathrm{p}^{1}$; silicon element is located in group IVA of the third period, and the electronic configuration is $[\mathrm{Ne}] 3 \mathrm{~s}^{2} 3 \mathrm{p}^{2}$. The two ionic forms, $\mathrm{Al}^{3+}$ and $\mathrm{Si}^{4+}$, have the same valence electron structure electronic configuration, and similar radii. The only difference is that $\mathrm{Al}^{3+}$ has one less positive charge than $\mathrm{Si}^{4+}$. Therefore, $\mathrm{Al}^{3+}$ can replace $\mathrm{Si}^{4+}$ in an orderly or disorderly manner, and the $\left[\mathrm{AlO}_{4}\right]$ and $\left[\mathrm{SiO}_{4}\right]$ together form the silicon-alumina-oxygen backbone. The charge change during the replacement process can be compensated by introducing other cations, and a stable ionic crystal is formed again. Metal cations other than the silicon-aluminum backbone can be easily replaced by other metal cations. This replacement will have a certain impact on its physical and chemical properties, but the impact on the backbone structure is very limited ${ }^{[13]}$.

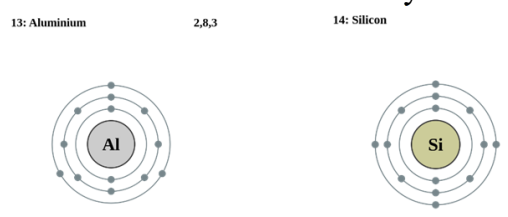

Fig. 7 Electronic configuration of aluminium and silicon

The top four elements in the crustal content are oxygen $\left(4.61 \times 10^{5}\right)$, silicon $\left(2.82 \times 10^{5}\right)$, aluminum $\left(8.23 \times 10^{4}\right)$ and iron $\left(5.63 \times 10^{4}\right)$. The content of aluminum in the earth's crust is second only to silicon, so it can replace silicon in the silicon-oxygen tetrahedral structure to form aluminosilicate.

The content of iron in the earth's crust is second only to aluminum, and it is theoretically possible to form a tetrahedral structure. However, its valence electron structure, electronic configuration and relative radius are quite different from those of silicon. In that case, it cannot replace silicon like aluminum and exist in silicon-based building materials in the form of tetrahedral structural units.

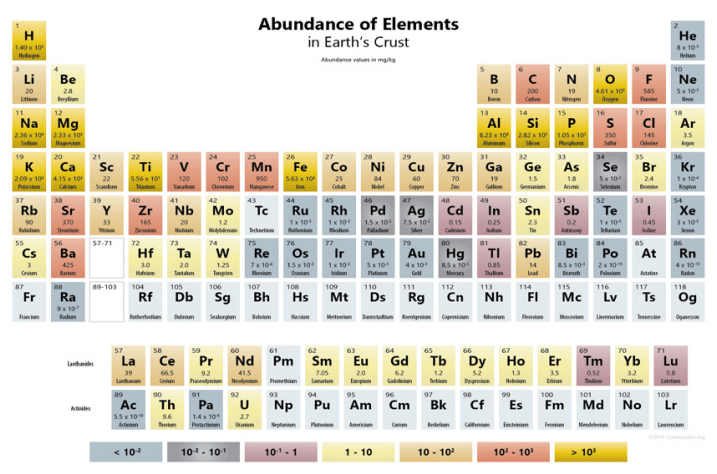

Fig. 8 Periodic table of chemical elements ${ }^{[16]}$

( This periodic table of chemical elements is marked by the relative value of the average milligram element content per kilogram of crustal composition. Non-natural elements are replaced by spaces)

\subsection{2 - $\mathrm{O}-\mathrm{H}$ and $-\mathrm{H}$}

The hydration reaction is the key reaction for Portland cement to gain strength. The hydration process of cement can be simplified into two stages of dissolution and precipitation. Products such as $\mathrm{H}_{4} \mathrm{SiO}_{4} 、\left[\mathrm{Al}(\mathrm{OH})_{4}\right]^{-}$、 $\mathrm{CaOH}^{+} 、 \mathrm{Ca}^{2+}$ and $\mathrm{SO}_{4}{ }^{2-}$ are obtained in the dissolution stage. In addition, $x(\mathrm{CaO})-\left(\mathrm{SiO}_{2}\right)-b\left(\mathrm{H}_{2} \mathrm{O}\right) 、 \mathrm{Ca}(\mathrm{OH})_{2}$ and ettringite are obtained in the precipitation stage ${ }^{[17]}$.

During the hydration process of cement, the hydroxide ions generated by the ionization of water molecules attack the metal cations in a nucleophilic way, forming -Ca-O-H, -Al-O-H and other hydroxyl-cation complexes. The hydrogen ions produced by the ionization of water molecules are electrophilic to replace cations, forming acidic molecular structures such as -Si-O-H or -S-O-H. The above-mentioned molecules or ions with a hydroxyl structure form hydrogen bonds(-O-H $\cdots \mathrm{O}-)$. The combined effect of valence bond and hydrogen bond causes structural rearrangement in the mixture system. Finally, the dehydration process between the hydroxyl groups form covalent bonds, resulting in a dense aluminosilicate framework structure with the good mechanical properties ${ }^{[18]}$. 


\subsection{Bonding Characteristics of Carbon-based Materials}

\subsection{1 -C6-O-C6- and -C-C-}

Wood and plastic are both carbon-based building materials. Wood has poor corrosion resistance and good biodegradability, while plastic has good chemical stability and poor biodegradability. The reason for the above difference is the difference in the nature of the chemical bond between wood and plastic.

Wood mainly refers to the xylem of trees, including cellulose, hemicellulose and lignin. Taking cellulose as an example, it is formed by polymerization of D-glucose monomer with $\beta$-1,4-glycosidic bond, and its valence bond is -C6-O-C6- ether bond formed by dehydration of hydroxyl between monosaccharides. The structural unit of lignin is a phenylpropane derivative. The molecules are connected to form a network structure through -C-O-C- ether bonds and a small amount of -C-C- bonds (Fig. 9), enhancing its strength and chemical stability.

Plastic building materials mainly include polyethylene, polypropylene, polychloropropylene, polytetrafluoroethylene and other polymers formed by monomers. Taking polyethylene as an example, its synthetic monomer is ethylene $\mathrm{H}_{2} \mathrm{C}=\mathrm{CH}_{2}$. During the polymerization reaction, the carbon-carbon double bond of the ethylene molecule breaks and re-forms the carbon-carbon single bond. The carbon-carbon single bond connects multiple monomers to form a long-chain polymer. The typical valence bond structure is - $\mathrm{C}-\mathrm{C}$ single bond. The valence bond(C-O-C) has strong polarity, and the orbital electron cloud of the carbon-oxygen single bond is biased toward the side of the oxygen atom. Therefore, the oxygen end has a slight negative charge and tends to be attacked by electrophiles, while the carbon end has a slight positive charge and tend to be attacked by nucleophiles. Therefore, the ether bond can be nucleophilicly substituted and hydrolyzed under natural mild acid-base conditions, leading to the disintegration of the long polymer chain. The carbon-carbon single bond (-C-C-) has good orbital electron cloud symmetry without polarity and high bond energy, so it is difficult for chain scission and degradation under natural conditions.

In addition, as a biological material, wood has a corresponding natural enzymatic degradation system, which can efficiently catalyze the cleavage of ether bonds to form monosaccharides, and finally completely degrade them. Plastics are synthetic high-molecular polymers, and there is no corresponding enzymatic degradation system in nature, which also causes the difference in degradability and corrosion resistance of wood and plastics.

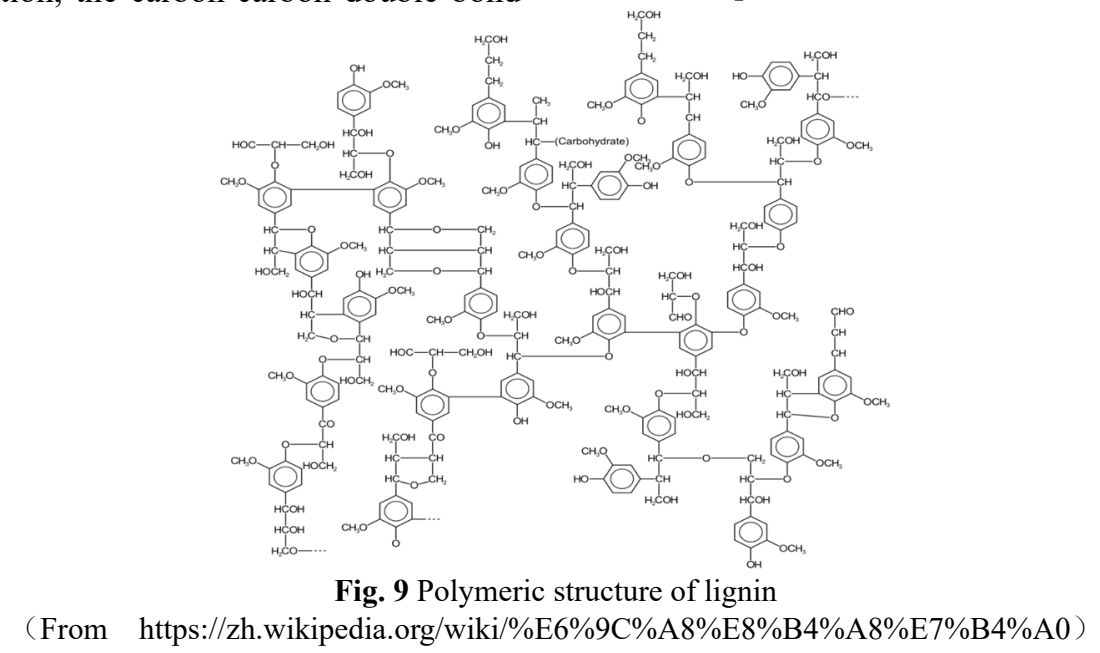

\subsection{2 -O-H $\cdots \mathrm{O}-$ and $-\mathrm{C}-\mathrm{O}-$}

In wood, cellulose, hemicellulose and lignin are cross-linked with secondary bond force and covalent bond force to form a stable high molecular polymer. The secondary bond forces include hydrogen bonds and van der Waals forces.

The existence of oxygen atoms is a prerequisite for the formation of hydrogen bonds. The hydrogen bond provides a valence bond force whose energy is higher than the van der Waals force but less than that of the covalent bond, and plays an important role in the stability of the cross-linking structure. From the structural chemistry point of view, the hydrogen bond is represented by $\mathrm{O}-\mathrm{H} \cdots \mathrm{O}^{[10]}$, where the $\sigma$ bond electron cloud of $\mathrm{O}-\mathrm{H}$ is biased towards the highly electronegative $\mathrm{O}$ atom, resulting in a positively charged hydrogen nucleus. Hydrogen nuclei are easily attracted by other highly electronegative oxygen atoms to form hydrogen bonds. Hydrogen bonds have the characteristics of low bond energy, low activation energy required for formation and destruction, and flexible space conditions for bond formation. In summary, the existence of hydrogen bonds improves the stability of the cross-linked structure of the three types of wood fibers.

The long chain molecules of cellulose contain a large number of hydroxyl groups, thereby forming a large number of hydrogen bonds. The long chains of cellulose molecules are arranged in parallel to form cellulose bundles, and each bundle is tightly combined by 100 to 200 parallel cellulose molecular chains through hydrogen 
bonds ${ }^{[7]}$. The excellent chemical stability and mechanical properties of cellulose depend on the structure of this hydrogen-bonded fiber bundle. Several fiber bundles are twisted together into a rope shape, embedding in lignin, just like steel bars placed in concrete, showing good mechanical properties such as high tensile strength.

Hemicellulose is a heteropolysaccharide polymer, which plays the role of compression resistance and filling structure in wood. Hemicellulose and cellulose mainly form the grid structure of plant cell walls through hydrogen bonds and van der Waals forces.

Lignin is a substance that surrounds the cell wall of the xylem. Lignin, cellulose, and hemicellulose are linked together at least at two sites through ether bonds or ester bonds (both containing -C-O- structures) ${ }^{[19]}$, and form carbohydrates complex under the combined action of hydrogen bonds and van der Waals forces. The formation of the complex increases the mechanical strength of the cell wall.

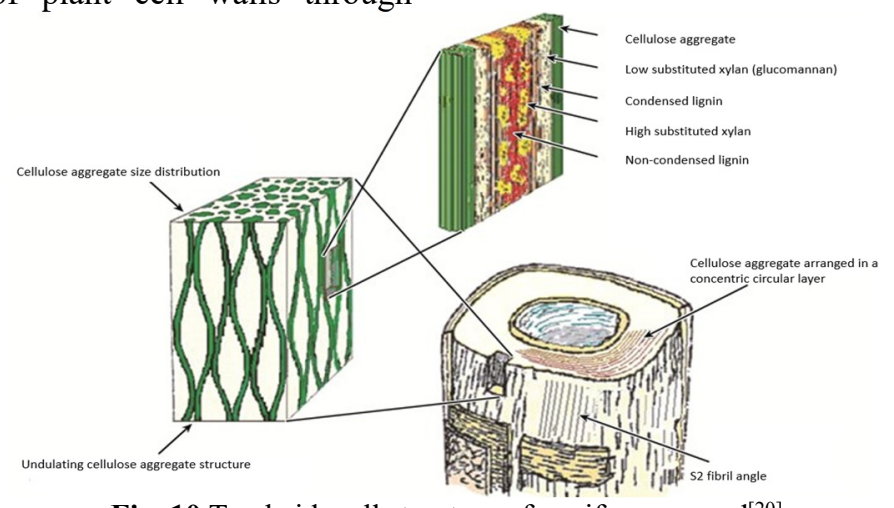

Fig. 10 Tracheid wall structure of coniferous wood ${ }^{[20]}$

\subsubsection{A Screening Method of Building Materials Based on Typical Valence Bonds}

The valence bond structure of hydrocarbon polymer determines the macroscopic properties of the material to a large extent, so the valence bond can be used as a basis for screening or designing building materials. For example, -C-O-C- in wood endows wood with degradability and good mechanical properties. Therefore, -C-O-C- can be used as the screening criteria for easily degradable materials to obtain degradable high molecular polymers such as polylactic acid and polyhydroxy fatty acid. Similarly, materials connected with ester groups (-C-O-CO-) as the main valence bond also have good degradability, and can also be used as a valence bond standard for the screening or design of degradable materials.

\subsection{Bonding Characteristics of Iron-based Building Materials}

\subsubsection{Fe-O and Al-O}

The elemental elements of iron and aluminum are both typical metal crystal structures and both have a high content in the earth's crust. However, aluminum is widely used in silicon-based building materials as the core element of aluminosilicate compounds, while iron is usually used in the form of elementary metal crystals. From the perspective of metal element extraction process, it is mainly the difference in the bond energy of Fe-O and Al-O ionic bonds that leads to the different forms of existence of the two in building materials.

In the metallurgical industry, aluminum and iron mainly exist in minerals in the form of oxides as raw materials. The standard Gibbs free energy of formation of $\mathrm{Al}_{2} \mathrm{O}_{3} \triangle_{\mathrm{f}} \mathrm{G}_{\mathrm{m}}{ }^{\theta}=-1582.3 \mathrm{~kJ} / \mathrm{mol}$, while the standard Gibbs free energy of formation of $\mathrm{Fe}_{2} \mathrm{O}_{3} \triangle_{\mathrm{f}} \mathrm{G}_{\mathrm{m}}{ }^{\theta}=-742.2$ $\mathrm{kJ} / \mathrm{mol}^{[10]}$. It can be seen that the Al-O bond energy is much higher than the Fe-O bond energy. In other words, the activity of $\mathrm{Al}$ element is much higher than Fe element, leading to the different metal smelting methods: the active aluminum needs to be prepared by electrolysis using high-purity $\mathrm{Al}_{2} \mathrm{O}_{3}$ as raw material, while the relatively stable iron is directly obtained by carbon reduction.

In aluminum smelting process, firstly, it uses alkaline solution or sodium carbonate solution to treat bauxite ore to purify $\mathrm{Al}_{2} \mathrm{O}_{3}$. Then it electrolyzes molten $\mathrm{Al}_{2} \mathrm{O}_{3}$ to obtain aluminum element. The chemical process are as follows:

$$
\begin{gathered}
\mathrm{Al}_{2} \mathrm{O}_{3}+2 \mathrm{NaOH}+3 \mathrm{H}_{2} \mathrm{O} \rightarrow 2 \mathrm{NaAl}(\mathrm{OH})_{4} \\
\text { or: } \mathrm{Al}_{2} \mathrm{O}_{3}+\mathrm{Na}_{2} \mathrm{CO}_{3} \rightarrow 2 \mathrm{NaAlO}_{2}+\mathrm{CO}_{2} \\
2 \mathrm{NaAl}(\mathrm{OH})_{4}+\mathrm{CO}_{2} \rightarrow 2 \mathrm{Al}(\mathrm{OH})_{3}+\mathrm{Na}_{2} \mathrm{CO}_{3}+\mathrm{H}_{2} \mathrm{O} \\
2 \mathrm{NaAlO}_{2}+\mathrm{CO}_{2}+3 \mathrm{H}_{2} \mathrm{O} \rightarrow 2 \mathrm{Al}(\mathrm{OH})_{3}+\mathrm{Na}_{2} \mathrm{CO}_{3} \\
2 \mathrm{Al}(\mathrm{OH})_{3} \rightarrow \mathrm{Al}_{2} \mathrm{O}_{3}+3 \mathrm{H}_{2} \mathrm{O} \\
2 \mathrm{Al}_{2} \mathrm{O}_{3} \rightarrow 4 \mathrm{Al}+3 \mathrm{O}_{2}
\end{gathered}
$$

Industrial iron smelting uses hematite or magnetite as raw materials to react with coke in the ore furnace as follows:

$$
\begin{gathered}
\mathrm{C}+\mathrm{O}_{2} \rightarrow \mathrm{CO}_{2} \\
\mathrm{CO}_{2}+\mathrm{C} \rightarrow 2 \mathrm{CO} \\
\mathrm{Fe}_{3} \mathrm{O}_{4}+4 \mathrm{CO} \rightarrow 3 \mathrm{Fe}+4 \mathrm{CO}_{2} \\
\mathrm{Fe}_{2} \mathrm{O}_{3}+\mathrm{CO} \rightarrow 2 \mathrm{FeO}+\mathrm{CO}_{2} \\
\mathrm{FeO}+\mathrm{CO} \rightarrow \mathrm{Fe}+\mathrm{CO}_{2}
\end{gathered}
$$

For the refining of aluminum element in industry, both the purification process and the electrolysis process are high energy-consuming process. Moreover, the aluminum element in nature is mainly doped in the 
aluminosilicate framework in the form of $\left[\mathrm{AlO}_{4}\right]$. At the same time, iron oxide compounds widely exist in nature mainly in the form of hematite and magnetite. In other words, there are a lot of raw materials which can be directly used in industrial iron-making. The abundance of mineral raw materials such as bauxite which can be used for the extraction of aluminum element is not high. In addition, the strength of aluminum is lower than that of iron, and it is not suitable as the main structural material. Therefore, aluminum appears in building materials more in the form of aluminosilicate rather than the metal elementary substance.

\section{Conclusion}

From the perspective of elemental chemistry, this paper divides the six major building materials into silicon, carbon and iron systems. Starting from the chemical nature of their valence structure and electronic configuration, the three-element building materials system is explained systematically. Finally, we use the valence bond theory to explain the causes of the microstructure of commonly used building materials and their macroscopic properties.

The essential nature of element chemistry difference fundamentally determines the difference of its chemical structure. The oxygen-philic nature of silicon makes it easier to form silicon-oxygen tetrahedral units, which are then connected to form aluminosilicate ion crystals by sharing oxygen atoms; the connectivity nature of carbon makes it easy for carbon atoms to form carbon chains and cross-link each other to form hydrocarbon polymer; iron element has excellent mechanical properties such as ductility due to its special metal crystal structure.

Different elements are connected by valence bonds and the structure of valence bonds determines the macroscopic properties and application forms of building materials. The similar electronic configuration of aluminum ion and silicon ion determines that aluminum can be doped in the silicate framework to form aluminosilicate; wood mainly uses -C-O-C-valent bond structure to obtain good mechanical properties and degradability; iron and aluminum has different smelting processes due to the difference in iron-oxygen valence bond and aluminum-oxygen valence bond energy, which affects the existence of iron and aluminum in building materials. The above conclusions can provide perspectives on element chemistry theory and valence bond theory for the selection and design of advanced building materials.

\section{References :}

1. Brownell Blaine. Material strategies - innovative applications in architecture. New York: Princeton Architectural Press. 2012.

2. Andrea Deplazes. Constructing Architecture: Materials Process Structure. Switzerland. Basel: Birkhauser. 2005.
3. $\mathrm{Xu}$ Wei. The evolution and application of ceramic mural decoration, Tsinghua University, Beijing, 2004, pp. 4-17.

4. Xiaoxi Ma. Research on the application of glass material in architectural design, Xi'an University of Architecture and Technology, Xi'an, 2011, pp. 18-24.

5. H. Lei. Engineering Geology, WUT Press, 2015. (in Chinese)

6. Hunan University, Tianjin University, Tongji University, et al. Civil Engineering Materials, China Architecture \& Building Press, 2013. (in Chinese)

7. H. Lu, et al. Organic Chemistry, Chemical Industry Press, 2014. (in Chinese)

8. J. Pei, et al. Basic Organic Chemistry, Peking University Press, 2017. (in Chinese)

9. Fu Wei, Liao Xiangru, Wang Junfeng, et al., Lignin in plants, Bulletin of Biology. (02) (2004) 12-14. (in Chinese)

10. Bai Jitao, Building anti-seismic technology and its developing trend, Shanxi Architecture. 47(05) (2021) 52-55. (in Chinese)

11. Y. Ding. Design Principle of Steel Structure, Tianjin University Press, 2020. (in Chinese)

12. G. Zhou, L. Duan. Foundation of Structural Chemistry, Peking University Press, 2008. (in Chinese)

13. S. Mai, G. Zhou, W. Li. Advanced Inorganic Structural Chemistry, Peking University Press, 2006. (in Chinese)

14. [14] Z. Zhang. Inorganic Chemistry, USTC Press, 2008. (in Chinese)

15. T. Wang, H. Zhao. Principle of Concrete Structure, Tianjin University Press, 2017. (in Chinese)

16. Todd Helmenstine. Abundance of Elements in Earth's Crust-Periodic Table and List. (2020-09-28) [2021-03-14].https://sciencenotes.org/abundance-ofelements-in-earths-crust-periodic-table-and-list.

17. KONG Xiangming, LU Zichen, ZHANG Chaoyang. Recent development on understanding cement hydration mechanism and effects of chemical admixtures on cement hydration, Journal of the Chinese Ceramic Society. 45(02) (2017) 274-281. (in Chinese)

18. Li Linxiang, Xie Yongjiang, Feng Zhongwei, et al. Cement hydration mechanism and research methods, Concrete. (06) (2011) 76-80. (in Chinese)

19. TAO Yongzhen, GUAN Yingting. Study of chemical composition of lignin and its application, Journal of Cellulose Science and Technology. (01) (2003) 42-55. (in Chinese)

20. Li Anxin, Lv Jianxiong, Jiang Jiali. A review of wood cell wall structure and its rheological property, Scientia Silvae Sinicae. 53(12) (2017) 136-143. (in Chinese) 